\title{
Molecular diagnosis of Toxoplasma gondii infection in cerebrospinal fluid from AIDS patients
}

\author{
Yenisey Alfonso ${ }^{1}$, Jorge Fraga*1, Carlos Fonseca², Narciso Jiménez², \\ Taimy Pinillos ${ }^{2}$, Alberto J Dorta-Contreras ${ }^{3}$, Raymundo Cox ${ }^{1}$, Virginia Capó ${ }^{2}$, \\ Olga Pomier ${ }^{2}$, Francisco Bandera ${ }^{2}$ and Dora Ginorio ${ }^{1}$
}

Address: 'Parasitology Department, Institute of Tropical Medicine 'Pedro Kourí', PO Box 601, Marianao 13, Ciudad de La Habana, Cuba, ${ }^{2}$ Health Care Division, Institute of Tropical Medicine 'Pedro Kourí', PO Box 601, Marianao 13, Ciudad de La Habana, Cuba and ${ }^{3}$ Central Laboratory of Cerebrospinal Fluid (LABCEL), PO Box 10049, Ciudad de la Habana, Cuba

Email: Yenisey Alfonso - yenisey@ipk.sld.cu; Jorge Fraga* - fraga@ipk.sld.cu; Carlos Fonseca - carlosfg@ipk.sld.cu;

Narciso Jiménez - narciso@ipk.sld.cu; Taimy Pinillos - pinillos@finlay.quimefa.cu; Alberto J Dorta-Contreras - adorta@infomed.sld.cu;

Raymundo Cox - raymundo@ipk.sld.cu; Virginia Capó - vcapo@ipk.sld.cu; Olga Pomier - olgap@ipk.sld.cu;

Francisco Bandera - bandera@ipk.sld.cu; Dora Ginorio - dginorio@ipk.sld.cu

* Corresponding author

Published: 6 March 2009

Cerebrospinal Fluid Research 2009, 6:2 doi:10.1 186/1743-8454-6-2
Received: 7 January 2009

Accepted: 6 March 2009

This article is available from: http://www.cerebrospinalfluidresearch.com/content/6/1/2

(C) 2009 Alfonso et al; licensee BioMed Central Ltd.

This is an Open Access article distributed under the terms of the Creative Commons Attribution License (http://creativecommons.org/licenses/by/2.0), which permits unrestricted use, distribution, and reproduction in any medium, provided the original work is properly cited.

\begin{abstract}
Background: Toxoplasmic encephalitis (TE) is one of the most common opportunistic infections in immunocompromised patients. In Cuba, despite the highly active antiretroviral therapy, TE is still the most important cause of cerebral mass lesions in patients infected with the human immunodeficiency virus (HIV). The detection of Toxoplasma gondii by PCR may facilitate the diagnosis and follow-up of TE in acquired immunodeficiency syndrome (AIDS) patients by direct identification of parasite DNA in clinical samples. The aim of the present study was to evaluate a rapid PCR method using the $B I$ gene to detect $T$. gondii in cerebrospinal fluid (CSF) samples from patients with suspected TE.
\end{abstract}

Methods: CSF samples from AIDS and HIV-negative patients were analyzed. Patients were divided into two groups according to the Centre for Disease Control and Prevention (CDC) criteria for AIDS-related TE: AIDS patients with suspected neurotoxoplasmosis and AIDS and HIV-negative patients with other confirmed neurological diseases but no suspicions of TE. Predictive values, diagnostic accuracy, sensitivity and specificity of the PCR BI method were calculated.

Results: The results obtained from 190 patients showed that this assay has a good sensitivity and specificity (83.3\% and $95.7 \%$, respectively) for the diagnosis of TE in AIDS patients.

Conclusion: PCR using the $\mathrm{BI}$ gene and B22/B23 set of primers is a single, rapid and reliable method that may be valuable for discrimination between toxoplasmosis and other central nervous system (CNS) diseases. 


\section{Background}

Toxoplasmosis, caused by the protozoan Toxoplasma gon$d_{i i}$, is a common parasitic infection in humans which has a cosmopolitan distribution. The prevalence of $T$. gondii infection varies among different geographical regions. The infection is characterized by non-specific symptoms with the consequent formation of cysts that may remain in latent form in many organs [1]. Reactivation of a latent infection occurs in immunocompromised patients causing life-threatening disease, especially encephalitis $[2,3]$. In our country, toxoplasmic encephalitis (TE) is still the most important cause of cerebral mass lesions in patients infected with human immunodeficiency virus (HIV) [4]. Therefore, a rapid diagnosis of TE is crucial for these patients with impaired immune functions, because early diagnosis and treatment may improve the clinical outcome. Although brain biopsy can establish a definitive diagnosis of TE it is an invasive and risky procedure associated with significant morbidity and mortality, while only half of the TE cases are confirmed [5].

It is standard practice to establish the presumptive diagnosis of the disease according to the Centre for Disease Control and Prevention (CDC) criteria for acquired immunodeficiency syndrome (AIDS)-related TE [6], but this is not infallible. For example, anti-Toxoplasma immunoglobulin detection may be unreliable in immunodeficient individuals, who fail to produce significant titers of specific antibodies [7]. The clinical presentation is indistinguishable from other neurologic disease frequently occurring among these patients [8]. The so-called "typical" lesions in the brain, detected by computed tomography (CT) or magnetic resonance imaging (MRI) are found in about $90 \%$ of the cases. However, these highly suggestive images of TE are not pathognomonic [9]. Upon the detection of an intracerebral suggestive lesion, an empirical treatment is usually initiated. In which case, the subsequent clinical and radiological improvement of the patient is considered a good criterion for diagnosis confirmation. Nevertheless, this approach may be used excessively in areas with high $T$. gondii seroprevalence [10].

Since the above mentioned criteria establish only a presumptive diagnosis, the need for less invasive, more sensitive, rapid and specific diagnostic methods is crucial for immunocompromised patients. For this reason, several studies for the diagnosis of TE employing PCR on cerebrospinal fluid (CSF) and blood samples have been reported [8,11-17]. As a result, several sets of primers for different DNA targets have been designed and each one of them tested on a small number of biological samples from different body sites [18], making a general consensus presently impossible [19]. Moreover, no assays have been sufficiently optimized and validated with a large number of well-characterized specimens [18]. Thus, the evaluation of each PCR in a large number of patients is extremely important for comparative laboratory studies, especially when the variability of conditions such as in the molecular diagnosis of toxoplasmosis is high.

The aim of this study was to evaluate a rapid PCR for TE diagnosis, using a set of primers for the most extensively used molecular target in a large number of CSF samples from immunocompromised patients.

\section{Methods \\ Parasite preparation}

T. gondii RH tachyzoites $\left(2 \times 10^{5} / \mathrm{ml}\right)$ were inoculated intraperitoneally into five OF1 Swiss mice. Tachyzoites were harvested three days later by peritoneal lavage collected in $5 \mathrm{ml}$ of phosphate-buffered saline (PBS), and centrifuged at $1000 \times g$ for $10 \mathrm{~min}$. The pelleted parasites were resuspended and washed twice in PBS. Cells were counted in a Neubauer chamber and diluted in PBS to a concentration of $5 \times 10^{5}$ cells $/ \mathrm{ml}$.

\section{Patients}

Approval for the study was obtained from the ethical committees of the Institute of Tropical Medicine "Pedro Kourí" and "Miguel Enriquez" Hospital using international criteria. Patients were informed about the study and written informed consent was obtained from each one of them or their closest relative. Clinical, immunological, radiological and laboratory data were collected from clinical charts.

The study included a total of 132 AIDS patients admitted to the clinical wards at the Institute of Tropical Medicine "Pedro Kourí", and 58 samples of HIV-negative patients from "Miguel Enriquez" Hospital, both in Havana, Cuba. Neurological symptoms were present in all patients. Before specific therapy was started, a spinal tap was performed, to collect $1 \mathrm{ml}$ of CSF from each patient, and samples were stored at $-20^{\circ} \mathrm{C}$ until analyzed.

Patients were divided into two groups. Group I $(\mathrm{n}=48)$ consisted of AIDS patients with suspected neurotoxoplasmosis according to the CDC criteria for AIDS-related TE [6] which includes the following clinical and radiological features: I) recent onset of a consistent focal neurological abnormality with intracranial disease or reduced level of consciousness; II) a lesion having a mass effect evidenced by CT imaging and III) serum antibody to $T$. gondii or successful response to treatment of toxoplasmosis. Group II $(n=142)$ consisted of 84 patients with other AIDS-related disorders (25 neurocryptococcosis, 11 tuberculosis, 6 non-Hodgkin lymphoma, 9 viral meningitis, $12 \mathrm{HIV}$ encephalitis, 21 active febrile illness not suspected of being toxoplasmosis) and $58 \mathrm{HIV}$-negative patients with inflammatory or non-inflammatory neurological disease. 


\section{DNA extraction}

For the DNA to be used as positive control for PCR, the phenol-chloroform-isoamyl alcohol (25:24:1) extraction method was employed [20] on a previously-counted pellet of RH strain T. gondii cells. All CSF samples were individually concentrated by centrifugation at $3000 \times g$ for 10 min. Sediments were re-suspended in $40 \mu \mathrm{l}$ of lysis buffer (10 mM Tris-HCl pH 8.3, $1.5 \mathrm{mM} \mathrm{MgCl}_{2}, 50 \mathrm{mM} \mathrm{KCl}, 0.1$ mg of gelatin per $\mathrm{ml}, 0.5 \%$ Tween $20,20 \mu \mathrm{g}$ of proteinase $\mathrm{K}$ (Promega, Madison, USA) and incubated at $55^{\circ} \mathrm{C}$, with shaking for $90 \mathrm{~min}$. After inactivating the proteinase $\mathrm{K}$ at $94^{\circ} \mathrm{C}$ for $10 \mathrm{~min}$, the tubes were centrifuged at $10,000 \times \mathrm{g}$ for $5 \mathrm{~min}$, and the supernatants collected $[21,22]$.

\section{PCR analytical sensitivity and specificity}

To determine the PCR sensitivity, two-fold serial dilutions ranging from $5 \times 10^{5}$ to 1 cell of the parasite ( $\mathrm{RH}$ strain) were prepared and DNA was extracted as previously described [21,22]. The DNA obtained was used for PCR under the same conditions as for clinical samples. Specificity was determined by PCR amplification of DNA extracted from yeasts (Cryptoccocus neoformans, Candida albicans, Candida parapsilopsis), gram positive cocci (Staphylococcus aureus, Staphylococcus epidermidis, Streptoccocus pneumoniae), gram negative rods (Serratia marcescens, Pseudomona aeruginos, Escherichia coli, Haemophilus influen$z a e)$, gram negative coccus (Neisseria meningitides) and herpes virus (Herpes simplex, Epstein Barr, Varicela Zoster, Cytomegalovirus).

\section{Detection of T. gondii DNA by PCR}

From the CSF samples, T. gondii DNA was detected by the amplification of a fragment of 115-bp of B1 gene [23], using primers B22 and B23 as previously described by Bretagne et al. [24]. The reaction conditions were tested using a large number of modifications to optimize the PCR conditions: temperature for primer annealing $\left(58^{\circ} \mathrm{C}, 59^{\circ} \mathrm{C}\right.$, $\left.60^{\circ} \mathrm{C}\right), \mathrm{MgCl}_{2}$ concentration $(1.5,2.0,3.0,4 \mathrm{mM})$, Taq DNA polymerase concentration $(0.5,1.0,1.5,2.0,3.0 \mathrm{U})$ and primer concentration $(0.05,0.1,0.2,0.3,0.4 \mu \mathrm{M})$. Consequently the proportion of DNA from CSF samples in the mixture reaction was also optimized. The optimized amplification was performed in $25 \mu \mathrm{l}$ of reaction mixture containing $10 \mathrm{mM}$ Tris- $\mathrm{HCl}, \mathrm{pH} 8.5,50 \mathrm{mM} \mathrm{KCl}$, $1.5 \mathrm{mM} \mathrm{MgCl}_{2}, 0.2 \mu \mathrm{M}$ of each primer (B22 and B23), 200 $\mu \mathrm{M}$ of each deoxynucleoside triphosphate and 1.5 U Taq DNA polymerase (Promega). Ten microliters of extracted DNA from CSF samples were added as template. The PCR conditions were $94^{\circ} \mathrm{C}$ for $5 \mathrm{~min}$, followed by 35 cycles of $94^{\circ} \mathrm{C}$ for $30 \mathrm{~s}, 59^{\circ} \mathrm{C}$ for $30 \mathrm{~s}$, and $72^{\circ} \mathrm{C}$ for $30 \mathrm{~s}$ and a last extension step at $72^{\circ} \mathrm{C}$ for $10 \mathrm{~min}$.

Each amplification assay contained two negative controls (ultrapure water and a negative control for DNA extraction) and one positive control (DNA extracted from RH T. gondii tachyzoites). Physical separation for mixture preparation, DNA extraction and visualization of PCR products were carried out and decontamination procedures were used in all areas to avoid contamination by amplicons. The PCR products were analyzed by $2 \%$ agarose gel electrophoresis in tris-borate-EDTA (TBE) buffer and stained with ethidium bromide $(0.5 \mathrm{mg} / \mathrm{ml})$. The DNA fragments were visualized under UV illumination.

Clinical samples with positive PCR results were tested twice. For the negative samples, an inhibition test was performed to discard the presence of inhibitors. (i.e., DNA equivalent to 5 cells of $T$. gondii $\mathrm{RH}$ was added to the negative DNA sample).

\section{Statistical analysis}

Predictive values, diagnostic accuracy, sensitivity and specificity of the PCR B1 method were calculated using a $2 \times$ 2 contingency table and recognized formulae [25-27] in which the CDC criteria for TE were used as a "gold standard".

\section{Results}

To determine the usefulness of the PCR for the diagnosis of TE in immunocompromised patients, 190 CSF samples from AIDS and HIV-negative patients were studied. After optimization of PCR conditions (data not shown), the assay was sensitive enough to detect up to one tachyzoite of $T$. gondii. A representative agarose gel of PCR products is shown in Figure 1. In order to investigate the analytical specificity of PCR, DNA from a variety of microorganisms that could potentially be present in the CSF of AIDS patients was used as target for the PCR reaction. No amplification product was observed when DNA from these specimens was present in the mixture reaction, thus dem-

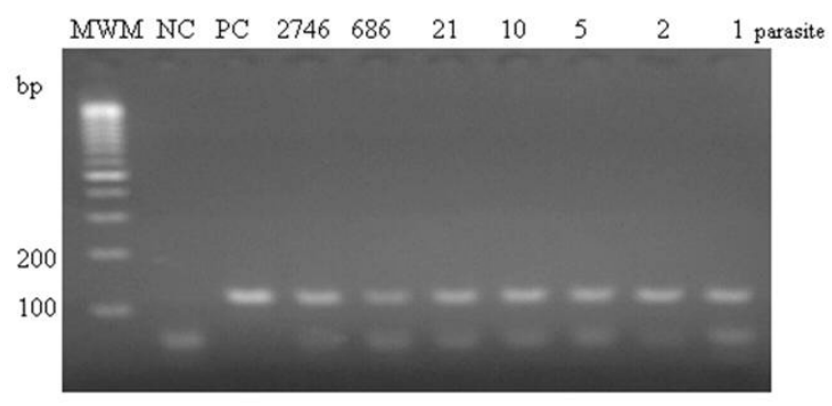

\section{Figure I}

Agarose gel electrophoresis analysis of PCR amplifications products performed with different numbers of tachyzoites. Lane MWM: Molecular Weight Marker 50 bp (Amersham, USA). Lane NC: Negative Control. Lane PC: Positive control. 
onstrating the absolute specificity of the set of PCR primers used (data not shown).

PCR diagnostic sensitivity and specificity were evaluated using the CDC criteria as the gold standard for AIDSrelated TE to detect $T$. gondii central nervous system (CNS) infection in patients, with and without suspected infection. The PCR results are shown in Table 1 . In group I, 40/ 48 patients with suspected TE had PCR positive results. In group II, corresponding to patients without suspected TE, six samples produced positive results while the remaining $136(95.7 \%)$ resulted negative. None of these positive samples were from HIV-negative patients.

The data represent a diagnostic sensitivity of $83.3 \%$ and a $95.7 \%$ of specificity. The positive predictive value of the assay was $86.9 \%$ while negative predictive value was $94.4 \%$. The diagnostic accuracy was $92.6 \%$, indicating the assay is reliable.

\section{Discussion}

The introduction of Highly Active Antiretroviral Therapy (HAART) has resulted in the decline of the incidence of opportunistic infections in the CNS in AIDS patients [5]. Particularly in Cuba, despite the universal use of HAART, TE is still the most important cause of cerebral mass lesions among HIV-infected patients [4]. Although a definitive diagnosis of the disease relies on the identification of parasites by histopathology, the clinical and radiological data could be complemented by a less invasive approach [17] that confirms the presence of parasites in body fluids, resulting in a better clinical management of the disease. The selection of the primers is also an essential step for successful PCR. Chabbert et al. [28] previously reported the high sensitivity of the B22 and B23 set of primers when compared with other $T$. gondii sequence primers. Due to their higher sensitivity, specificity and practicability, the use of these primers was recommended for the detection of $T$. gondii DNA in immunocompromised patients where Brazilian researchers found they gave a good diagnostic sensitivity $[16,17]$. The $\mathrm{B} 1$ gene has been the most widely used target for the diagnosis of toxoplasmosis [19]. Hence, it was expected that the B1 PCR employed here would prove to be useful for the detection of T. gondii CNS infection. The evaluation of the large cohort used in this study adds weight to this hypothesis.

The results of the analytical sensitivity assay (1 parasite) was similar to previous studies that used sets of primers for B1 gene and was able to detect either a single organism from a crude cell lysate $[23,29]$ or 10 tachyzoites in presence of 100,000 human leukocytes [23]. These results show that very small numbers of $T$. gondii can be detected. The diagnostic sensitivity found in this study was $83.3 \%$ (Table 1). This means that 40 patients out of 48 with suspected neurotoxoplasmosis gave positive results for the presence of $T$. gondii, demonstrating that PCR is a diagnostic technique with relatively high sensitivity for TE in CSF samples. Eight AIDS patients with suspected TE had negative results and in one of them the necropsy confirmed the diagnosis of TE. None of these patients received treatment before the spinal tap. Therapy is an important element for the sensitivity of PCR, since previous studies reported that anti-Toxoplasma therapy decreases diagnostic sensitivity, especially when the samples are collected after the first week of treatment [30].

The sensitivities previously reported for TE diagnosis from CSF range widely in value $(17 \%-100 \%)$ with an average of 59\% (97/164 patients with TE from 17 studies) [19]. The sensitivity obtained in our work corresponds to the range reported for CSF and was superior to several studies that use CSF and nested reactions for $\mathrm{B} 1$ gene $[12,31]$. Also, it is noteworthy that the sensitivity of a PCR depends on many factors such as physicochemical conditions of the reaction, the concentration and nature of DNA target, the selected PCR primers and the nucleic acid extraction method [32]. In our case, optimization of the PCR conditions was carefully carried out enhancing the analytical sensitivity and specificity of the assay. An additional advantage is the frequency in which the $\mathrm{B} 1$ gene is present in the parasite genome [33]. Is well known that the number of copies of the DNA target in the genome of interest is an essential factor for the assay sensitivity and also that the use of the same primers does not necessarily ensure identical results for different laboratories [32]. In

Table I: Relation between the PCR results from CSF samples and the presence or absence of toxoplasmic encephalitis (TE).

\begin{tabular}{cccc}
\hline PCR results & Patients with TE (I) & Patients without TE (II) & Total No. of samples \\
\hline Positive PCR & $40(83.3 \%)^{1}$ & 6 & 46 \\
\hline Negative PCR & 8 & $136(95.7 \%)^{2}$ & 144 \\
\hline Total No. of samples & 48 & 142 & 190 \\
\hline
\end{tabular}

\footnotetext{
I Diagnostic sensitivity
}

2 Diagnostic specificity 
relation to this, a study carried out in Brazil by Vidal et al. [16] used CSF samples from immunocompromised patients and the same set of primers for the B1 gene as used here. They reported $100 \%$ sensitivity while our sensitivity for the present study was lower, even though similar PCR conditions were used. On the other hand the above mentioned study included 12 patients, while we used samples from four times more patients with TE. Nevertheless, the DNA extraction methods differed between the laboratories and this fact may play an important role in the assay performances and significantly influence the assay sensitivity. In our experience, as previously reported, the DNA extraction protocol was chosen after comparing four different extraction methods [22]. In comparison with other in-house DNA extraction methods the protocol here used is rapid, reproducible, and simple and it could be recommended for routine PCR diagnosis of TE in places with limited resources.

The laboratory conditions are crucial to raise the sensitivity and specificity of the PCR technique, especially when it is used on clinical specimens. For this reason, an inhibition test was carried out for every sample producing negative results in order to rule out the presence of PCR inhibitors. Moreover, negative controls were used to check for contamination and all the necessary cautions were taken in order to prevent possible risks of contamination that frequently happens in this kind of reaction.

As for the dignostic specificity, all six sample from AIDS patients without suspected TE with positive results, corresponded to patients presenting with other AIDS related diseases but without clinical or radiological evidence of cerebral toxoplasmosis upon admission. Although specificity of PCR in the diagnosis of TE has been extremely high in most of reports, false positive results have been described $[16,17,34,35]$, particularly among immunocompromised patients, for whom it has been proposed that parasitemia may exist prior to, or during the course of cerebral toxoplasmosis [18]. In our case, clinical surveillance of these six patients was not made and the possibility of subsequent TE could not be excluded, making the results inconclusive. It is possible that the sporadic breakdown of tissue cysts may provide enough DNA in the CSF for parasite detection, in contrast to the large amount of parasite DNA that is found in evident TE [34]. These six individuals could have still some immunological capacity to destroy parasites released from the sporadic breakdown of cysts, and so prevent the reactivation of TE.

\section{Conclusion}

PCR using the B22 and B23 primer sets for the diagnosis of TE in AIDS patients is a rapid, simple, reliable, sensitive and specific method, and can be used as a practical and alternative tool for the diagnosis of TE in immunocom- promised patients. The method is easy to perform and less prone to contamination compared with nested PCR reaction and will help patients to gain the benefit of early antiToxoplasma treatment.

\section{Competing interests}

The authors declare that they have no competing interests.

\section{Authors' contributions}

JFN designed the study, performed coordination and drafted the manuscript. YA carried out the molecular studies and drafted the manuscript. CF, NJ, OP, FB, TP and AJDC participated in the design, data collection and review the clinical profiles of patients and the patients grouped. RC carried out the immunoassays. VC carried out the pathology studies and contributed to the manuscript. DG participated in the laboratory coordination and contributed to the manuscript. All authors read and approved the final version of the manuscript.

\section{Acknowledgements}

The authors would like to thank all colleagues from the Institute of Tropical Medicine Pedro Kouri who kindly donated the DNA from bacteria's, fungus, and viruses used in analytical specificity test.

\section{References}

I. Dunlop O, Rootwelt V, Sannes M, Goplin A, Abdelnoor M, Skaug K, Baklien K, Skar A, Melby K, Myrvang B, Bruun JN: Risk of toxoplasmic encephalitis in AIDS patients: Indications for prophylaxis. Scand J Infect Dis 1996, 28:71-73.

2. Hill D, Dubey JP: Toxoplasma gondii: transmission, diagnosis and prevention. Clin Microbiol Infect 2002, 8:634-640.

3. Dubey JP: Toxoplasma gondii. Medical Microbiology 4th edition. 1996, 84: [http://gsbs.utmb.edu/microbook/ch084.htm]. The University of Texas Medical Branch at Galveston, Galveston, Tex

4. Pérez J, Pérez D, González I, Díaz-Jidy M, Orta M, Aragones C, Joanes J, Santón M, Lantero MI, Torres R, Gonzáles A, Alvarez A: Approaches to the management of AIDS in Cuba: Case study. World Health Organization; 2004.

5. Antinori A, Ammassari A, De Luca A, Cingolani A, Murri R, Scoppettuolo G, Fortini M, Tartaglione T, Larocca LM, Zannoni G, Cattani P, Grillo R, Roselli R, lacoangeli M, Scerrati M, Ortona L: Diagnosis of AIDS-related focal brain lesions: a decision-making analysis based on clinical and neuroradiologic characteristic combined with polymerase chain reaction assay in CSF. Neurology 1997, 48:687-694.

6. Centre for Disease Control and Prevention: From the Centers for Disease Control and Prevention. 1993 revised classification system for HIV infection and expanded surveillance case definition for AIDS among adolescents and adults. JAMA 1993, 269(6):729-730.

7. Hierl T, Reischl U, Lang P, Hebart H, Stark M, Kyme P, Autenrieth IB: Preliminary evaluation of one conventional nested and two real-time PCR for the detection of Toxoplasma gondii in immunocompromised patients. I Med Microbiol 2004, 53:629-632.

8. Contini C, Fainardi E, Cultrera R, Canipari R, Peyron F, Delia S, Paolino E, Granieri E: Advanced laboratory techniques for diagnosing Toxoplasma gondii encephalitis in AIDS patients: significance of intrathecal production and comparison with PCR and ECL-western blotting. J Neuroimmunol 1998, 92:29-37.

9. Porter S, Sande M: Toxoplasmosis of the central nervous system in the acquired immunodeficiency syndrome. N Eng J Med 1992, 327(23): 1643-1648.

10. Raffi F, Aboulker JP, Michelet C, Reliquet V, Pelloux H, Huart A, Poizot-Martin I, Morlat P, Dupas B, Mussini JM, Leport C: A prospec- 
tive study of criteria for the diagnosis of toxoplasmic encephalitis in 186 AIDS patients. AIDS 1997, I I:177-184.

II. Schoondermark-van de Ven EJ, Galama C, Kraaijeveld J, van Druten J, Meuwissen J, Melchers W: Value of the polymerase chain reaction for the detection of Toxoplasma gondii in cerebrospinal fluid from patients with AIDS. Clin Infect Dis 1993, 16:66I-666.

12. Novati R, Castagna A, Morsica G, Vago L, Tambussi G, Ghezzi S, Gervasoni C, Bisson C, De Arminio M, Lazarin A: Polymerase Chain Reaction for Toxoplasma gondii DNA in the cerebrospinal fluid of AIDS patients with focal brain lesions. AIDS 1994 8:169I-1694.

13. Dupon M, Cazenave J, Pellegrin JL, Ragnaud JM, Cheyrou A, Fischer I, Leng B, Lacut JY: Detection of Toxoplasma gondii by PCR in tissue culture in cerebrospinal fluid and blood of human immunodeficiency virus-seropositive patients. J Clin Microbiol I995, 33:242I-2426.

14. Cinque $\mathrm{P}$, Vago L, Dahl H, Britting M, Terreni MR, Fornara C, Sracca $S$, Castagna A, Monforte AD, Wahren B, Lazzarin A, Linde A: Polymerase chain reaction on cerebrospinal fluid for diagnosis of virus-assiociated opportunistic disease of the central nervous system in HIV-infected patients. AIDS 1996, 10:95I-958

15. Julander I, Martin C, Lappalainen M, Guy E, Isberg B, Evengaírd B: Polymerase chain reaction for diagnosis of cerebral toxoplasmosis in cerebrospinal fluid in HIV-positive patients. Scand J Infect Dis 200I, 33:538-54I.

16. Vidal JE, Colombo FA, Penalva de Oliveira AC, Focaccia R, PereiraChioccola VL: PCR assay using cerebrospinal fluid for diagnosis of cerebral toxoplasmosis in Brazilian AIDS patients. J Clin Microbiol 2004, 42:4765-4768.

17. Colombo FA, Vidal JE, Penalva de Oliveira PE, Hernandez AV, Bonasser-Filho F, Nogueira RS, Focaccia R, Pereira-Chioccola VL: Diagnosis of cerebral toxoplasmosis in AIDS patients in Brazil: importance of molecular and immunological methods using peripheral blood samples. J Clin Microbiol 2005, 43:5044-5047

18. Weiss JE: DNA probes and PCR for diagnosis of parasitic infections. Clin Microbiol Rev 1995, 8: I I3-130.

19. Bastien P: Molecular diagnosis of toxoplasmosis. Trans R Soc Trop Med Hyg 2002, 96 Suppl I:S205-S2 I 5.

20. Sambrook J, Fritsch EF, Maniatis T: Molecular cloning, a laboratory manual Cold Spring Harbor: Cold Spring Harbor Laboratory Press; 1989.

2I. Gross U, Roggenkamp A, Janitschke K, Heeseman H: Improved sensitivity of the polymerase chain reaction for detection of $T$. gondii in biological and human clinical specimens. Eur J Clin Microbiol Infect Dis 1992, I I:33-39.

22. Alfonso $Y$, Fraga J, Cox R, Bandera F, Pomier O, Fonseca C, Ginorio D, Torres G, Capo V: Comparison of four DNA extraction methods from cerebrospinal fluid for the detection of Toxoplasma gondii by polymerase chain reaction in AIDS patients. Med Sci Monit 2008, I 4(3):MTI-MT6.

23. Burg JL, Grove CM, Pouletty P, Boothroyd JC: Direct and sensitive detection of a pathogenic protozoan, Toxoplasma gondii, by polymerase chain reaction. J Clin Microbiol 1989, 27: I787-I792.

24. Bretagne S, Costa JM, Vidaud M, Tran Van Nhieu J, Fleury-Feith J Detection of Toxoplasma gondii by competitive DNA amplification of bronchoalveolar lavage samples. J Infect Dis 1993 , 168: I585- 1588 .

25. Altman DG, Bland JM: Statistics Notes: Diagnostic tests I: sensitivity and specificity. BMJ 1994, 308:1552.

26. Altman DG, Bland JM: Statistics Notes: Diagnostic tests I: predictive values. $B M]$ 1994, 309: 102

27. Hoorfar J, Wolffs P, Radstrom P: Diagnostic PCR: validation and sample preparation are two sides of the same coin. APMIS 2004, I I 2:808-8|4

28. Chabbert E, Lachaud L, Crobu L, Bastien P: Comparison of two widely used PCR primer systems for detection of Toxoplasma in amniotic fluid, blood, and tissues. J Clin Microbiol 2004, 42: 1719-1722

29. Priya J, Calderon MM, Gilman RH, Quispe ML, Cok J, Ticona $E$ Chavez V, Jimenez JA, Chang MC, Lopez MJ, Evans CA: Optimization and evaluation of a PCR assay for detecting toxoplasmic encephalitis in patients with AIDS. I Clin Microbiol 2002, 40:4499-4503

30. Cingolani A, de Luca A, Ammassari A, Murri R, Linzalone A, Grillo R, Antinori A: PCR detection of Toxoplasma gondii DNA in CFS from the differential diagnosis of AIDS-related focal brain lesions. J Med Microbiol 1996, 45:472-476.

31. Contini C, Cultrera R, Seraceni S, Segala D, Romani R, Fainardi E, Paola C, Adriano L, Salvatore D: The role of stage-specific oligonucleotide primer in providing effective laboratory support for the molecular diagnosis of reactivated Toxoplasma gondi encephalitis in patients with AIDS. I Med Microbiol 2002, 5 I:879-890.

32. Bastien P, Procop GW, Reischl U: Quantitative real-time PCR is not more sensitive than "conventional" PCR. J Clin Microbiol 2008, 46:1897-1900.

33. da Silva AV, Langoni $\mathrm{H}$ : The detection of Toxoplasma gondii by comparing cytology, histopathology, bioassay in mice, and the polymerase chain reaction (PCR). Vet Parasitol 200I, 97:191-198.

34. Nicoll S, Burns SM, Brettle RP, Leen CS: A comparison of two methods of gene amplification for the diagnosis of Toxoplasma gondii in AIDS. J Infect 1996, 33: 177-|83.

35. Pelloux H, Dupoy-Camet J, Angelici MC, Aspock H, Bessieres M, Blatz R, del Pezzo M, Girault V, Gratzi R, Holberg-Petersen M, Johnson J, Kruger D, Lappalainen M, Naessens A, Olsson M: A second European collaborative study on polymerase chain reaction for Toxoplasma gondii, involving 15 teams. FEMS Microbiol Letters $1998,165: 23 \mid-237$
Publish with Bio Med Central and every scientist can read your work free of charge

"BioMed Central will be the most significant development for disseminating the results of biomedical research in our lifetime. "

Sir Paul Nurse, Cancer Research UK

Your research papers will be:

- available free of charge to the entire biomedical community

- peer reviewed and published immediately upon acceptance

- cited in PubMed and archived on PubMed Central

- yours - you keep the copyright
BioMedcentral 